\title{
AN EXTENSION OF UCHIYAMA'S RESULT ASSOCIATED WITH AN ORDER PRESERVING OPERATOR INEQUALITY
}

\author{
TAKAYUKI FURUTA AND EIZABURO KAMEI
}

Abstract. Let $A, B$ and $C$ be positive invertible operators and also let $r, s$ and $t$ be non-negative real numbers such that $t \geqslant s$ and $(r, t) \neq(0,0)$. Then the following (I) and (II) hold and follows from each other.

(I) If $A^{t} \ll B^{t} \nabla_{\lambda} C^{t}$ (i.e., $\left.\log A^{t} \leqslant \log \left(B^{t} \nabla_{\lambda} C^{t}\right)\right)$ for all $t \geqslant 0$, then

$$
f(t)=\left\{A^{\frac{r}{2}}\left(B^{t} \nabla_{\lambda} C^{t}\right) A^{\frac{r}{2}}\right\}^{\frac{s+r}{t+r}} \quad \text { is an increasing function of } t .
$$

(II) If $A^{t} \gg B^{t} !_{\lambda} C^{t}$ (i.e., $\log A^{t} \geqslant \log \left(B^{t} !_{\lambda} C^{t}\right)$ ) for all $t \geqslant 0$, then

$$
h(t)=\left\{A^{\frac{r}{2}}\left(B^{t} !_{\lambda} C^{t}\right) A^{\frac{r}{2}}\right\}^{\frac{s+r}{t+r}} \quad \text { is a decreasing function of } t,
$$

where $B \nabla_{\lambda} C$ and $B !_{\lambda} C$ are the arithmetic mean and the harmonic mean respectively.

In particular we have

(I') If $A^{t} \ll B^{t} \nabla_{\lambda} C^{t}$, then

$$
A^{\frac{r}{2}}\left(B^{S} \nabla_{\lambda} C^{S}\right) A^{\frac{r}{2}} \leqslant\left\{A^{\frac{r}{2}}\left(B^{t} \nabla_{\lambda} C^{t}\right) A^{\frac{r}{2}}\right\}^{\frac{s+r}{t+r}}
$$

(II') If $A^{t} \gg B^{t} !{ }_{\lambda} C^{t}$, then

$$
A^{\frac{r}{2}}\left(B^{S} !_{\lambda} C^{S}\right) A^{\frac{r}{2}} \geqslant\left\{A^{\frac{r}{2}}\left(B^{t} !_{\lambda} C^{t}\right) A^{\frac{r}{2}}\right\}^{\frac{s+r}{t+r}} .
$$

These are extensions of the recent results in Uchiyama [12].

Mathematics subject classification (2000): 47A63.

Key words and phrases: Chaotic order, Furuta inequality, arithmetic mean and harmonic mean.

\section{REFERENCES}

[1] T. ANDO, On some operator inequalities, Math. Ann. 279 (1987), 157-159.

[2] M. FusII, Furuta's inequality and its mean theoretic approach, J. Operator Theory, 23 (1990), 67-72.

[3] M. FuJII AND E. KAMEI, Furuta's inequality for the chaotic order, I, II, Math. Japon. 36 (1991), 603-606 and 717-722.

[4] M. FUJII, T. FURUTA AND E. KAMEI, Furuta's inequality and application to Ando's theorem, Linear Algebra and Appl. 179 (1993), 161-169.

[5] T. FurutA, $A \geqslant B \geqslant 0$ assures $\left(B^{r} A^{p} B^{r}\right)^{1 / q} \geqslant B^{(p+2 r) / q}$ for $r \geqslant 0, p \geqslant 0, q \geqslant 1$ with $(1+2 r) q \geqslant p+2 r$, Proc. Amer. Math. Soc. 101 (1987), 85-88.

[6] T. FURUTA, Elementary proof of an order preserving inequality, Proc. Japan Acad. 65 (1989), 126.

[7] T. FURUTA, Applications of order preserving operator inequalities, Operator Theory: dvances and Applications, 59 (1992), 180-190.

[8] E. KAMEI, A satellite to Furuta's inequality, Math. Japon, 33 (1988), 883-886.

[9] E. KAMEI, Chaotic order and Furuta inequality, to appear in Scientiae Mathematicae.

[10] F. Kubo AND T. ANDO, Means of positive linear operators, Math. Ann. 246 (1980), 205-224.

[11] K. TAnahashi, Best possibility of the Furuta inequality, Proc. Amer. Math. Soc. 124 (1996), 141-146.

[12] M. UCHIYAMA, An operator inequality related to Jensen's inequality, preprint. 